\title{
Duke University School of Law
}

\author{
Responsibility and the Normative Order Assumption \\ Author(s): Barbara Baum Levenbook \\ Source: Law and Contemporary Problems, Vol. 49, No. 3, Responsibility (Summer, 1986), pp. \\ 81-88 \\ Published by: Duke University School of Law \\ Stable URL: http://www.jstor.org/stable/1191626 \\ Accessed: 24/02/2009 10:23
}

Your use of the JSTOR archive indicates your acceptance of JSTOR's Terms and Conditions of Use, available at http://www.jstor.org/page/info/about/policies/terms.jsp. JSTOR's Terms and Conditions of Use provides, in part, that unless you have obtained prior permission, you may not download an entire issue of a journal or multiple copies of articles, and you may use content in the JSTOR archive only for your personal, non-commercial use.

Please contact the publisher regarding any further use of this work. Publisher contact information may be obtained at http://www.jstor.org/action/showPublisher?publisherCode=dusl.

Each copy of any part of a JSTOR transmission must contain the same copyright notice that appears on the screen or printed page of such transmission.

JSTOR is a not-for-profit organization founded in 1995 to build trusted digital archives for scholarship. We work with the scholarly community to preserve their work and the materials they rely upon, and to build a common research platform that promotes the discovery and use of these resources. For more information about JSTOR, please contact support@jstor.org.

Duke University School of Law is collaborating with JSTOR to digitize, preserve and extend access to Law and Contemporary Problems. 


\title{
RESPONSIBILITY AND THE NORMATIVE ORDER ASSUMPTION
}

\author{
Barbara BaUm LeVEnbooK*
}

I should say at the outset that I agree with Professor Weinreb ${ }^{1}$ in thinking that the utilitarian rationale for criminal punishment is inadequate, and in supposing what I will call the retributive creed: in order for criminal punishment to be justified, the person punished must deserve the punishment. I think that no one deserves punishment for bringing about some consequence unless he is morally responsible for that consequence, and I also think that at least some of the problematic rules of criminal liability discussed by Weinreb sometimes allow persons to be punished for consequences for which they are not morally responsible. Alternatively, these rules allow for punishment of those who are only partly morally responsible for the consequences of their actions, but not responsible enough to deserve punishment. It follows from these beliefs that the broad scope of these liability rules cannot be justified.

Weinreb sets out to discover a way in which someone who accepts the retributive creed can nonetheless defend the felony murder rule and several other rules of criminal liability. He finds it in the ontological assumption of "a normative order." 2 It is extremely difficult to understand what he means by "a normative order" in a way that makes his claims consistent. He says that the assumption of a normative natural order is the assumption that "the causally determinate background of our actions is itself according to our desert."3 As I understand it, his assertion can be restated as follows: sometimes when one brings about $\mathrm{x}$ by doing $\mathrm{y}$, one deserves all the causal conditions that, when combined with one's act, ensure that by doing y one brought about $\mathbf{x}$. One also deserves all the conditions that cause one to do $y$. Both the causes of one's doing $y$, and those factors that, combined with one's doing $y$, resulted in one's bringing about $x$ by doing $y$, are causal conditions of one's action of bringing about $\mathbf{x}$. Admittedly, this interpretation is inconsistent with some of Weinreb's other assertions about the normative order assumption. In particular, it is hard to reconcile with his suggestion that the contradiction between responsibility and desert introduced by assuming a "causally determinate background of human action" is

\footnotetext{
Copyright $\odot 1986$ by Law and Contemporary Problems

* Associate Professor of Philosophy, Department of Philosophy and Religion, North Carolina State University.

1. This article responds to Weinreb, Desert, Punishment, and Criminal Responsibility, Law \& Contemp. Probs., Summer 1986, at 47.

2. Id. at 73 .

3. Id. at 53 .
} 
"overcome" by the normative order assumption. ${ }^{4}$ As I shall argue below, this assumption not only fails to overcome a contradiction, it generates one. ${ }^{5}$

My interpretation of the normative order assumption is also difficult to reconcile with Weinreb's claim that in some applications of the felony murder rule there is "strong evidence of a normative disorder."6 Weinreb, however, has the same problem; his contention that the normative order assumption overcomes the contradiction between responsibility and desert is also inconsistent with this claim. Weinreb may be claiming that in felony murder, the defendant does not deserve the causal conditions of his bringing about the death. If this is true, however, it is impossible to explain in what sense Weinreb believes that by treating the felony murderer as morally responsible for the death "it is as if we exculpate nature" because we "restor[e] . . . normative order."7

In addition, it is difficult to reconcile my interpretation with his claim that the idea of a normative order is the core of the Christian conception of the Eternal Law as postulated by Thomas Aquinas. ${ }^{8}$ Aquinas believed that the universe is ruled by divine reason, and that the things to which human beings have a natural inclination are good. He believed, too, that it is possible to infer certain moral precepts from the ends of these inclinations. These beliefs have little bearing on the question of desert in any particular case. Weinreb also alludes to the doctrine of original sin, from which it follows that we all deserve evil unless we redeem ourselves by our actions and choices in certain ways. ${ }^{9}$ The original sin doctrine could form the basis for imposing liability in problematic cases. It fails to explain, however, why liability should not be imposed in cases where the accused has committed no crime but nonetheless failed to redeem himself. It is, therefore, overbroad as a useful normative order assumption for the purposes of retributivism.

Given my interpretation of the normative order assumption, our ordinary judgments about the limits of human responsibility and desert for culpable conduct seem arbitrary, unprincipled, and entirely a matter of convention. ${ }^{10}$

4. Id. .

5. See infra p. 84.

6. Similarly, in his rationalizing explanation of the rule that one who mistakenly goes to the aid of an aggressor and kills the aggressor's victim is liable for the death, he says, "unless the person who intervenes is liable, the occurrence of the harm . . . is too strong evidence of normative disorder." Weinreb, supra note 1, at 77 (emphasis deleted).

7. Id. at 76 .

8. Id. at 75

9. Id.

10. Weinreb seems sometimes to agree with this statement. He says that the problematic legal doctrines that support certain results about responsibility in certain cases "contradict our usual, wellsettled understanding of the conditions in which responsibility and susceptibility to punishment attach ...."Id. at 73. With exceptions that will be pointed out below, however, those results are supported by the normative order assumption. See infra at p. 85. Weinreb certainly takes them to be so supported. He admits that as we ordinarily think about these matters, we believe a person can deserve good or bad "without insisting that he have deserved all the factors that might explain his conduct," Weinreb, supra note 1 , at 74 . This admission amounts to a denial of the normative order assumption. He then says, " $[\mathrm{t}]$ here is no basis for" our ordinary assumption, and "convention aside it is just as convincing to affirm the opposite ...." Id. at 74-75. Weinreb also argues that on the 
For we ordinarily do not blame people for regrettable consequences they helped to bring about when those consequences were neither intended nor foreseeable by them, nor the result of an act that was careless with regard to its consequences. Assuming that on the normative order assumption those people deserve all the causal conditions of their bringing about these consequences, and assuming that bringing about these consequences is culpable, it is puzzling that we do not blame those people for the consequences.

As an answer to this puzzle, one might argue that in such cases the bringing about of consequences was entirely beyond the agent's control. This answer, however, can be dismissed. The ordinary successful murderer, one who kills as he intends to kill, brings about death in part through conditions entirely beyond his control. Yet we have no hesitation in regarding him as blameworthy. It is entirely beyond the successful gunman's control, for example, that the bullet was not at the last moment deflected by an unforeseeable gust of wind, a descending chandelier, or an out-of-control automobile, that his victim did not at the last moment succumb to a muscular spasm or a fit of coughing that would have moved him out of range. If determinism is true, and if the causes of events must antedate them, then in one sense every human act is largely beyond the actor's control, for no one controls the ultimate antecedent causes of his own actions. The question for a philosopher is whether this sense of "beyond the actor's control" is one that matters for moral responsibility; it is not clear that it does matter.

At this point I must, with great hesitation, challenge Professor Weinreb's interpretation of American criminal law. I hesitate because he is a legal expert and I am not. Nonetheless, as I read the law, the mere existence of causal factors beyond the actor's control is not normally regarded as an excuse. ${ }^{11}$ Admittedly, some judges have talked as if it were an excuse, or at least as if consistency demands that it be so treated. ${ }^{12}$ Yet homicide rules seem to provide for criminal liability of the successful gunman even though there are causal conditions like those mentioned above that he could not control. One might argue that it is with regard to just such cases that these rules are unclear and need judicial interpretation, but my sense is that most judges would interpret them straightforwardly enough. The attorney who tried to defend

normative order assumption, which views desert as separable from freedom, the "sharp break between the special, troubling cases and all the straightforward cases of criminal liability . . that we perceive is one of convention, albeit deep convention, only." Id. at 77.

11. If I read him correctly, Weinreb says that it is an excuse. He states: "[S]o far as the operation of the criminal law is concerned, Judge Bazelon was correct . . . If it is established that the defendant's act is the product of causes beyond his control, criminal responsibility is removed." $I d$. at 62 (footnote omitted). Perhaps Weinreb would distinguish criminal liability and criminal responsibility here. He may not have wished to assert that criminal liability is removed, that is, that under these conditions the defendant has an excuse in law. He may instead have wished to assert that moral responsibility is removed, and that under these conditions the defendant ought to have an excuse in law.

12. For example, see Weinreb's discussion of Judge Bazelon's opinion in Durham v. United States, 214 F.2d 862, 876 (D.C. Cir. 1954), overruled, United States V. Brawner, 471 F.2d 969 (D.C. Cir. 1972), supra note 1 , at 62 . 
his client by introducing evidence that his client could not have controlled the failure of the victim to duck at the crucial time would, it seems to me, be laughed out of court.

Weinreb puts the normative order assumption to three uses, all of which are suspect. First, he uses the assumption to overcome the paradox in the "abstract idea of desert."13 My interpretation of Weinreb's normative order assumption, however, when combined with Weinreb's assumptions about the ordinary concept of desert, actually creates a contradiction concerning desert. The contradiction can be generated by making the following assumptions:

(1) To deserve punishment for bringing about $\mathrm{x}$ by doing $\mathrm{y}$, one's act must be free. ${ }^{14}$

(2) To deserve punishment for bringing about $\mathrm{x}$ by doing $\mathrm{y}$, one must deserve all the causal conditions that, when combined with one's act, ensure that by doing $y$ one brings about $x .^{15}$

(3) If one acts freely, one's free act itself will be "fully determined." 16

(4) Therefore, to deserve punishment for bringing about $\mathrm{x}$ by doing $\mathrm{y}$, one must deserve all the conditions that fully determine that one will do y. ${ }^{17}$

(5) At least some of the conditions that fully determine someone's doing $y$ (or that, with someone's doing $y$, fully determine that by doing $y$ he will do $\mathrm{x})$ are beyond his control.

(6) If conditions are beyond one's control, they cannot be the product of one's freedom.

(7) If a condition is not the product of one's freedom, then one cannot deserve it.

Now one must add either:

(8) Sometimes people deserve punishment for bringing about a result by doing some act;

13. Weinreb calls it a "contradiction" and an inconsistency in the "abstract idea of desert." Id. at 58. He says that the inconsistency is betokened by our "willingness to excuse conduct in certain circumstances but not others ...."Id. However, he later says the difficulty he is discussing is that desert "seems to require that a person's acts be both free and determinate." Id. at 74. Weinreb refers to this combination as a "contradiction." Id. at 58.

14. Weinreb makes this assumption explicitly. "Unless [a person's acts] are free, the person cannot be said to be morally responsible, and desert is out of the question." Id. at 74 .

15. Weinreb states: "[U]nless the conditions in which a person acts are fully determined according to his desert, they are arbitrary from a moral point of view ...." Id. One reaches the assumption in question by adding that if the causal conditions under which one acts are arbitrary from a moral point of view, one cannot deserve punishment for his act.

16. Weinreb makes it clear that the assumption that all acts occur in "a determinate natural order," id., contributes to the contradiction he thinks can be generated. He says that "the causally determinate background of human action undermines our conclusions about individual responsibility and ... desert . ..."Id. at 53. He later states, "the general premise that conduct is subject to causal order applies universally ... ." Id. at 78. Weinreb's causal order appears to be one in which all events are fully determined, that is, one in which for every event $\mathrm{E}$, there are antecedent causes $\mathrm{C}$ such that once $\mathrm{C}$ occurs, the occurrence of $\mathrm{E}$ is inevitable. It certainly is what Strawson, whom he cites, means. Id. at 59-60, citing P.F. Strawson, Skepticism and Naturalism: Some VARIETIES 38 (1985).

17. Weinreb states, “[U]nless such deserved conditions fully determine [one's] action, an attribution of desert . . . is morally arbitrary." Id. at 74 . 
or

(9) Sometimes people act freely. ${ }^{18}$

It should be obvious that these assumptions generate contradictions. From claims (4), (5), (6), and (7) one can derive:

(8') No one ever deserves punishment for bringing about a result by doing some act.

This proposition, however, contradicts claim (8). Notice, though, that (4), a consequence of the normative order assumption, is essential to the generation of this contradiction. Nevertheless, I must admit that one can generate another contradiction without the normative order assumption if, in addition, one assumes:

(10) If all the fully determining conditions of one's act are not the product of one's freedom, one does not act freely.

Weinreb may be tacitly making assumption (10), but it can be challenged as highly suspect. From (3), (5), (6), and (10) one can derive:

$\left(9^{\prime}\right)$ No one ever acts freely.

This proposition contradicts claim (9). Propositions (1) and (9') generate a contradiction about desert. From their combination it follows that:

(8') No one ever deserves punishment.

As before, proposition ( $8^{\prime}$ ) contradicts (8). But it seems clear that making the normative order assumption at this point will not avoid contradiction.

Far from overcoming a contradiction about desert, then, the normative order assumption generates one. Perhaps Weinreb believes that the original contradiction I generated can be overcome by discarding proposition (7). In order to discard this proposition one must assume that we deserve to be the sorts of people we are, to have the heredity we have. ${ }^{19}$ Our traits and characters are part of the causal background of our actions. But the causal background does not stop with the individual. If one discards proposition (7) and retains the normative order assumption, it follows that individuals deserve the rest of the causal background of their acts, including, for example, a faulty gun, or a gust of wind that changes a bullet's trajectory. It also includes acts of others that depend for their occurrence on the individual's initial actions, such as rescue attempts or acts of self preservation. These dependent acts are part of the causal conditions of an individual's own actions, in particular, of those acts that can be described as bringing about one thing by doing another. So, for example, the drowning shipwreck victim who grabs a raft away from another drowning victim may be (unintentionally, of course) bringing about his own death at the hands of the other, who responds by grabbing the raft back. Thus, when proposition (7) is abandoned and the normative order assumption is retained, it follows that the one who is killed deserves his killer's reaction of grabbing the raft.

18. Weinreb makes this statement as a contributing assumption. Id.

19. He emphasizes the apparent nondesert of our own character traits, and the role character plays in causing our acts. Id. at 56-61. 
Weinreb's second use of the normative order assumption is either to justify or to explain rationally certain problematic rules of liability. He claims that the assumption is reflected by the problematic rules of liability. ${ }^{20}$ I find this assertion unconvincing. The normative order assumption is useful in the sense that it offers one rationale for creating some of the liability rules. But Weinreb does not show that it provides a rationale for all of them, that it offers the only account of the rules it explains, or that its accounting for them would be a virtue. Each of these objections will be elaborated in turn.

The normative order assumption does not account for at least one of the rules it is postulated to explain: the special rule of liability for death that occurs when two innocent persons struggle to stay alive. ${ }^{21}$ For if people sometimes deserve the causal conditions of the things they bring about, why does not the innocent person who, though acting to save his own life, must pose a threat to another's survival, not deserve his own death at the hands of the other? As discussed above, ${ }^{22}$ the victim does cause his own death, although unintentionally. A similar argument can be made with respect to the victim of manslaughter who provokes his own death at the hands of another. If he caused the other's act, then he brought about his own death. If a victim brings about his own death, then the conduct of his assailant presumably cannot be culpable, because it was a causal condition of the result the victim brought about, and was therefore deserved by the victim. It follows that his assailant does not deserve punishment.

If the normative order assumption is offered as an explanation for the perennial attractiveness of the remaining problematic rules, there are rivals to it. These rules may be resistant to change, and perennially attractive, simply because people accept the following line of argument:

\footnotetext{
We will maximize social utility and minimize disutility if we punish people for certain dangerous acts. One of the reasons these acts are dangerous is that they create the risk of killings. If we punish each commission of these acts sufficiently severely to deter enough people from committing them, so that few killings occur as a result of them, we will inflict a large amount of pain, which is an undesirable consequence. It is possible to reduce the amount of pain inflicted and still achieve substantially the same deterrence by punishing people fairly severely for committing these acts, but punishing them even more severely if one of the foreseeable risks of these acts, death, occurs.
}

This sort of reasoning, although it may be based on false empirical assumptions or indefensible moral assumptions, is sufficient to account for the attractiveness of the felony murder and misdemeanor manslaughter rules. Similarly, it also accounts for the attractiveness of the rule applying to "factually impossible" attempts. By imposing less severe punishment on those whose attempts fail only because of circumstances beyond their control than that imposed on those whose attempts are successful, the rule attains the maximum deterrence at the lowest cost.

20. Id. at 73 .

21. For Weinreb's discussion of this rule, see id. at 68-71.

22. See supra p. 85. 
Weinreb might reply that, given the weaknesses of utilitarianism, the normative order assumption is the only successful account of the felony murder and misdemeanor manslaughter rules, as well as the rule of lessened punishment for factually impossible attempts. That the normative order assumption can offer a rationale for these rules, however, is not obviously a virtue of the assumption. It would be a virtue only if it were good to justify these rules, or if it were more certain that the rules were morally justifiable than it is certain what constitute the grounds of desert. I suspect, however, that the rules are not morally justifiable, in which case one ought to reject an assumption that leads to the conclusion that the rules are justified.

Moreover, showing that the normative order assumption successfully accounts for the problematic rules of liability would require either that the assumption be true or, if beyond the realm of truth and falsity, that it be at least as well grounded in our ordinary beliefs as any contrary assumption. Weinreb admits that the assumption is neither true nor false. ${ }^{23}$ Thus, only the second alternative remains. However, the normative order assumption is not as well grounded in our ordinary beliefs, for all the reasons given above: it is not necessary in order to account for the attractiveness of some problematic rules of liability, it does not account for other rules, and it is inconsistent with our more usual beliefs about particular cases of responsibility.

Weinreb's third use of the normative order assumption is to explain noncontroversial judgments of responsibility. He claims that the normative order assumption is "essential to our resolution of untroubling cases" of moral responsibility, and is "a structural element of human experience as we know it." 24 Here, I take it he means that, at least in part, we think that in a case of where the gunman succeeds in killing his victim as intended, he is responsible for some of the consequences of his acts although he was not in complete control of all of the causes of these consequences. This assertion, though, does not entail the normative order assumption. Weinreb assumes that if a murderer is responsible for some of the consequences of his acts, although he was not in complete control of all the causes of these consequences, then he deserves all the causal conditions of the killing (that is, premises (2) and (4), above). ${ }^{25}$ But why not simply deny the assumption? Although we might have to admit that the problematic rules of criminal liability are unjustifiable, that is not too high an intellectual price to pay. Weinreb believes the rules are not "simply . . . mistake[s]," 26 but his belief can be defended, if at all, as a consequence of a theory of criminal responsibility and desert, and ought not to be a presupposition of one.

I must concede to Weinreb that, on the normative order assumption, the ordinary limits we place on moral responsibility and blameworthiness seem arbitrary. But from that admission it would surely be a mistake further to

23. Weinreb, supra note 1 , at 73 .

24. Id.

25. See supra p. 84.

26. Weinreb, supra note 1 , at 73 . 
conclude, as Weinreb does, that these limits cannot be defended in any principled way. ${ }^{27}$

What Professor Weinreb's article does establish is that a principled theory is needed to explain and defend the way most decisions about moral responsibility and its limits are commonly made, both within and without the law. There are puzzles here so unsettling and important that they either have to be explained by some theory of moral responsibility and desert, or our intuitions must be revised. We need to explain how the ordinary successful gunman, who kills in part through circumstances he cannot control, is morally responsible for the death which those circumstances cause. At the same time we need to explain how the armed robber, whose act causes someone else to act independently, thereby causing the death of another, is not morally responsible for that death. In the end, Weinreb may be right that no adequate theory can be devised to consistently explain these judgments. However, it would be premature to conclude that an adequate theory cannot be devised. 